\title{
The Dermal Papilla: An Instructive Niche for Epithelial Stem and Progenitor Cells in Development and Regeneration of the Hair Follicle
}

\author{
Bruce A. Morgan \\ Department of Dermatology, Harvard Medical School and Cutaneous Biology Research Center, Massachusetts \\ General Hospital, Boston, Massachusetts 02129 \\ Correspondence: bruce.morgan@cbrc2.mgh.harvard.edu
}

\begin{abstract}
The dermal papilla (DP) of the hair follicle is both a chemical and physical niche for epithelial progenitor cells that regenerate the cycling portion of the hair follicle and generate the hair shaft. Here, we review experiments that revealed the importance of the DP in regulating the characteristics of the hair shaft and frequency of hair follicle regeneration. More recent work showed that the size of this niche is dynamic and actively regulated and reduction in DP cell number per follicle is sufficient to cause hair thinning and loss. The formation of the DP during follicle neogenesis provides a context to contemplate the mechanisms that maintain DP size and the potential to exploit these processes for hair preservation or restoration.
\end{abstract}

$T_{\text {him }}^{\text {he }}$ he direct biological importance of hair for thermoregulation, protection, and adaptive coloration has been largely circumvented in humans, but its effects on well being remain significant. The hair follicle also serves as an important model system. The broad diversity of hair morphologies and decline in hair quality common with age makes this a useful system to study the mechanisms that specify organ size and shape, as well as their failure during aging. The fact that the hair-producing segment of the follicle undergoes periodic regeneration in the adult from a dedicated stem cell pool makes it an important model to study stem cell biology and regeneration.

The bulk of the hair follicle is composed of keratinocytes, the epithelial cells that comprise the hair shaft itself as well as the encircling inner and outer root sheaths (Fig. 1). However, a specialized mesenchymal population, the dermal papilla (DP), plays a critical role in directing the activities of these keratinocytes to form the follicle and generate the hair shaft. Active communication between the DP or its precursors and the epithelial compartment regulate many aspects of follicle biology. The DP remains intimately associated with the epithelial progenitor populations of the follicle despite the dynamic changes in follicle structure as it goes through cycles of active growth (anagen), degeneration of the lower follicle (catagen), quiescence (telogen), and regeneration (Fig. 1). Its role in the biology of the adult follicle is inseparable from this interaction, both because the ultimate biological output of the DP is the hair shaft and inductive signaling between these two compart-

Editors: Anthony E. Oro and Fiona M. Watt

Additional Perspectives on The Skin and Its Diseases available at www.perspectivesinmedicine.org

Copyright (C) 2014 Cold Spring Harbor Laboratory Press; all rights reserved; doi: 10.1101/cshperspect.a015180

Cite this article as Cold Spring Harb Perspect Med 2014;4:a015180 


\section{B.A. Morgan}

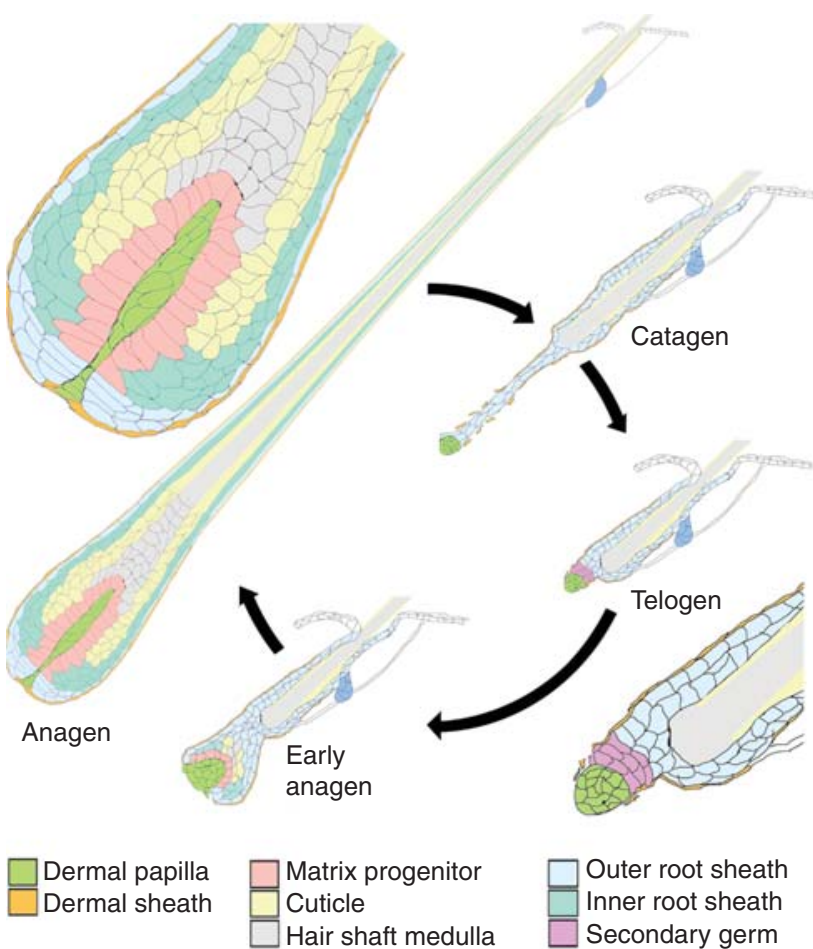

Figure 1. Follicle structure during the hair cycle. The structure of the hair follicle at different stages of the hair cycle is shown. The hair shaft is produced during the anagen phase. At this stage, the follicle projects deep beneath the epidermis. The hair bulb at the base of the follicle is shown magnified above. Matrix progenitor cells (rose) abutting the DP (bright green) generate progeny that proliferate a few more times in the hair matrix before differentiating into the cell types of the inner root sheath (light green) and hair shaft cuticle, cortex (yellow), and medulla (gray). The hair shaft and IRS are extruded through the outer root sheath (blue) until the hair shaft projects from the surface of the skin and the IRS is shed. Blue cells abutting the DP are the progenitors of the proximal outer root sheath. The keratinocyte compartment is encased by dermal sheath cells (orange). At the end of the growth phase, most keratinocytes of the lower follicle either apoptose or differentiate into the base of the hair club. The DP is drawn upward by the receding epithelial strand and comes to rest at the base of the permanent follicle during the quiescent telogen stage. Keratinocytes of the secondary germ (pink) lie between the DP and the "bulge." These proliferate in early anagen to regenerate the hair bulb and engulf the DP.

ments is required for the formation, maintenance, and changing activity of the DP.

\section{DP IN DEVELOPMENT AND THE HAIR CYCLE}

The first morphologically detectable step in hair follicle development is the formation of an epidermal placode. The placode recruits cells from the underlying dermis to form a local increase in dermal cell density beneath the epidermal placode, the dermal condensate. Gene expression changes suggest that active signaling between this population and the placode stabilizes both populations and drives further development of the hair peg. The dermal condensate becomes the DP as it further compacts and is engulfed by the growing hair peg (Muller-Rover et al. 2001). It remains embedded in the hair bulb throughout the period of active hair shaft elaboration. During this growth period, the cells in physical apposition to the DP act as the progenitor population that produces the inner root sheath (IRS) and hair shaft (Fig. 1) (Legue and Nicolas 2005). These precursor cells remaining adjacent 
to the DP continue to divide, whereas their descendants displaced from the basement membrane soon cease dividing, are extruded toward the skin surface, and differentiate into cell types of the IRS and hair shaft according to their position of origin along the proximal/distal axis of the DP. At the end of the growth phase, the progenitor population abutting the DP either differentiates or dies (Ito et al. 2004; Greco et al. 2009). The hair shaft and IRS are drawn upward to the permanent portion of the follicle, whereas most of the cells of the surrounding outer root sheath apoptose. The DP forms a compact ball of cells that is drawn to the base of the resting follicle, in physical contact with keratinocytes below the bulge region referred to as the secondary germ. The DP remains a compact ball, whereas the follicle is in the telogen or resting phase. At the start of a new anagen phase, the DP becomes less compact and the subsequent regeneration of the lower follicle is quite similar to initial morphogenesis as the DP is engulfed by the nascent hair bulb and becomes more elongated. Thus, throughout the hair cycle, the DP is well positioned to provide inductive signals that guide the activity of the cells that generate and regenerate the follicle. The DP serves as the physical niche for progenitor cells in both the growth and resting phases and its proximity to these cells and their immediate progeny provides the opportunity for inductive signaling to direct both proliferation of progenitors and differentiation of their derivatives. Melanocytes embedded in the epithelium of the hair bulb derive from progenitors in the secondary germ and bulge region and provide pigment to the forming hair. The DP is well positioned to regulate their activity as well.

Gene expression in the DP suggests that in addition to a physical niche for progenitors, the $\mathrm{DP}$ is a source of diffusible signals that influence follicular epithelium. Global expression profiles reveal dynamic expression of secreted molecules in the DP during the hair cycle (Stenn and Paus 2001; Rendl et al. 2005; Driskell et al. 2009; Greco et al. 2009). Both interspecific tissue recombination experiments between epidermis and dermis and analysis of specific signaling pathways in different species have indicated that the mecha- nisms guiding early development of epidermal appendages are broadly conserved across taxonomic classes, including birds and mammals (Dhouailly 1973; Song et al. 1996, 2004; Jung et al. 1998; Morgan et al. 1998; Noramly and Morgan 1998; Jiang et al. 1999; Noramly et al. 1999; Laurikkala et al. 2002; Houghton et al. 2005, 2007; Drew et al. 2007; Wells et al. 2012; Huh et al. 2013). Thus, DP extirpation and reengraftment experiments that showed a requirement for the DP in the growth and regrowth of feathers implied a similar requirement for the DP in normal hair follicle growth and regeneration (Lillie and Wang 1941; Wang 1943). This was confirmed by analogous experiments in vibrissa (whisker) follicles of the rat (Oliver 1967). Follicles failed to regenerate after surgical removal of the lower third of the follicle, but implantation of DP was sufficient to restore regeneration. Heterotopic tissue recombination experiments between epidermis and dermis in oviparous species also established the concept that the size, shape, and spacing of ectodermal appendages is dictated largely by the dermis (Dhouailly et al. 1998). Although analysis of tissue recombinants in mammals has been more limited in scope, naïve mouse epidermal cells also adopt the hair type appropriate to the region of dermis with which they are combined (Kollar 1970).

The role of the mesenchyme in directing morphology of the hair produced is maintained in the mature DP. Implantation of whisker DP into heterotopic sites promotes the formation of whisker-like hairs either by incorporating into existing, smaller follicles or by the de novo induction of hair follicles (Oliver 1970; Pisansarakit and Moore 1986; McElwee et al. 2003). Pelage DP cells also show these properties. Rat pelage DP can induce pelage-type follicles in glabrous skin (Reynolds and Jahoda 1992). The engraftment of rat cells derived from pelage DP into mouse pelage follicles results in the formation of larger hair shafts from mouse follicular epithelium that are more similar to those observed in rat (Biernaskie et al. 2009). Thus, different DP cells can induce keratinocyte populations to produce different hair morphologies (Driskell et al. 2009). 
B.A. Morgan

\section{GENETIC MANIPULATION OF DP IN VIVO}

Extirpation and transplantation experiments show a critical role for the DP, but the high degree of coordination and feedback between the DP and follicular epithelium complicates attempts to further define the role of the DP by surgical manipulations that affect both compartments. More recently, noninvasive genetic approaches have shifted the focus to pelage follicles for analysis of DP cell activities. Four pelage hair types with distinctive morphologies are interspersed in the dorsal fur coat. Guard hairs are straight, smoothly tapered, and longer than other hair types. They comprise a few percent of the hair coat and perform a mechanosensory function distinct from that of the other hair types (Li et al. 2012). Awl hairs are thick, straight, and bluntly tapered at the distal end. Auchenes are similar to awls, but have a single obtuse angle bend. Awl and auchene hairs comprise $~ 30 \%$ of the pelage, although the majority of hairs are zigzag hairs, which are the thinnest hairs and have multiple bends.

Although it is possible to stimulate hair follicle production in the adult mouse (Ito et al. 2007), hair follicles are normally generated during mid-late embryogenesis and the perinatal period. Three waves of follicle formation occur at e14.5, 16.5, and around birth. Follicles formed in the first wave make guard hairs throughout the life of the mouse (Dry 1927). Second, wave follicles make predominantly awl and auchene hairs in the first hair cycle, whereas the last generate follicles that make zigzag hairs in the first cycle. The fact that follicles forming in these three waves produce different hair types led to speculation that the DP cells formed at different times are intrinsically different, and this intrinsic difference specifies alternative hair morphologies. However, the type of hair produced by a follicle is not fixed. Most follicles that make auchene hairs in the first hair cycle switch to the production of awl hairs in the second, whereas a subset of follicles that made zigzag hairs in the first coat switch to the production of auchene or awl hairs (Dry 1927; Chi et al. 2013). This interconversion be- tween different pelage hair types in the same follicle contrasts with the ectopic or heterospecific transplantation experiments that showed qualitatively different DP cells of distinct embryological origin could impose different morphogenetic programs on follicular keratinocytes. In this case, the same DP cell population directs the adoption of three distinct morphogenetic programs on the same keratinocyte progenitor pool.

\section{DP CELL NUMBER CORRELATES WITH HAIR SIZE AND TYPE}

One character that distinguishes the different pelage hair types is size. A correlation between the size of the DP and the size of the hair shaft has been noted in healthy human hair follicles (Scott and Eckel 1958). This is maintained in the context of progressive hair loss in which the size of the follicle and hair it produces is reduced in successive hair cycles until a miniaturized vellus hair follicle results (Fig. 2) (Miranda et al. 2010). A similar correlation is observed in injury-induced whisker regeneration experiments in the rat (Ibrahim and Wright 1982). In the mouse, the number of cells in the DP correlates with the type of hair produced (Sharov et al. 2006; Chi et al. 2013). For awl or auchene hairs, the thickness of the hair produced also correlates with DP cell number. Furthermore, as follicles switch to the production of larger hair types, this correlation is maintained by a corresponding increase in DP cell number (Chi et al. 2013). The increase in the DP cell number within a follicle can occur in part by recruitment of new cells to the DP (Chi et al. 2010), although proliferation of DP cells may also contribute to this expansion. The correlation between DP size and hair size and type produced in successive cycles by the same follicle raises the question of whether DP cell number has a direct effect on the morphogenetic program. This question, as well as postulated roles of the DP in the regulation of the hair cycle and morphogenesis of the hair shaft have become accessible to experimental analysis with the advent of techniques that allow specific genetic manipulation of the DP in vivo. 


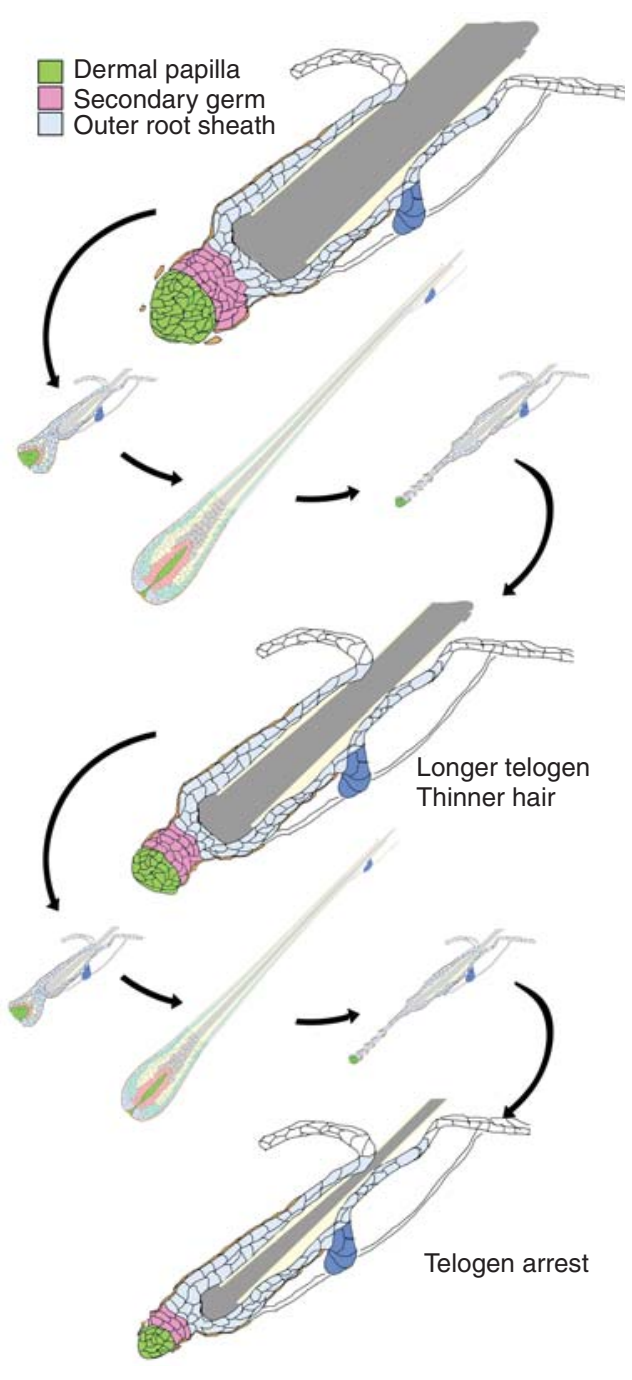

Figure 2. Follicular miniaturization leads to arrest in telogen. Progressive hair thinning and loss is accompanied by a reduction in the size of the DP and secondary germ in successive hair cycles. As the follicle shrinks, it spends more time in telogen and may ultimately arrest in this phase.

\section{INITIATION OF THE ANAGEN PHASE}

It had been proposed that the DP sends signals to the stem cells of the follicular bulge to initiate a new anagen phase (Sun et al. 1991). Recent work demonstrating that activation of the keratinocytes abutting the DP is the first step of anagen strengthened the apparent relevance of this hypothesis (Greco et al. 2009). Manipulation of
The Dermal Papilla of the Hair Follicle

signaling pathways in follicular keratinocytes has shown that activation of the Wnt / $\beta$-catenin pathway promotes anagen initiation, whereas both bone morphogenetic protein (BMP) signaling and fibroblast growth factor (FGF)-18 (expressed from the keratinocytes coating the club hair) prolong the telogen phase (Botchkarev et al. 2001; Van Mater et al. 2003; Kobielak et al. 2007; Kimura-Ueki et al. 2012; Leishman et al. 2013). The DP expresses Wnts, R-spondins, FGFs, and Noggin, all of which can promote follicle growth and contribute to initiating follicular regeneration (Reddy et al. 2001; Rendl et al. 2005). It has been proposed that regeneration of the follicle entails initial activation of signaling between mesenchyme and epithelium that results in a metastable state poised between quiescence and activation (Plikus et al. 2011). Successful positive feedback between epithelium and mesenchyme can push this signaling activity over a threshold that locks in an activated state. In this model, a signal "initiating anagen" occurs in the context of ongoing low-level signaling that may include both keratinocyte and DP sources. Nevertheless, a requirement for DP activity to initiate anagen was shown by celltype-specific ablation of the $\beta$-catenin gene in DP (Enshell-Seijffers et al. 2010). Several of the signaling genes that promote follicular proliferation or anagen initiation when their products are exogenously applied, including FGF-7, FGF-10, and noggin, show reduced expression when $\beta$-catenin signaling is blocked in the DP during anagen. Follicles that lack a functional $\beta$ catenin gene in the DP enter the telogen phase, but fail to reenter anagen.

The genetic ablation of $\beta$-catenin in the DP was strong evidence of the importance of the DP in anagen initiation, but it could be argued that a defect arising in the prior anagen or catagen phase contributed to the failure of follicular regeneration. This argument was refuted by Greco and colleagues, who used a two-photon confocal microscope to specifically ablate the DP from single follicles in the skin of a live mouse during the first telogen phase (Rompolas et al. 2012). These follicles failed to enter anagen when the surrounding follicles did and instead remained in telogen for the length of time they 


\section{B.A. Morgan}

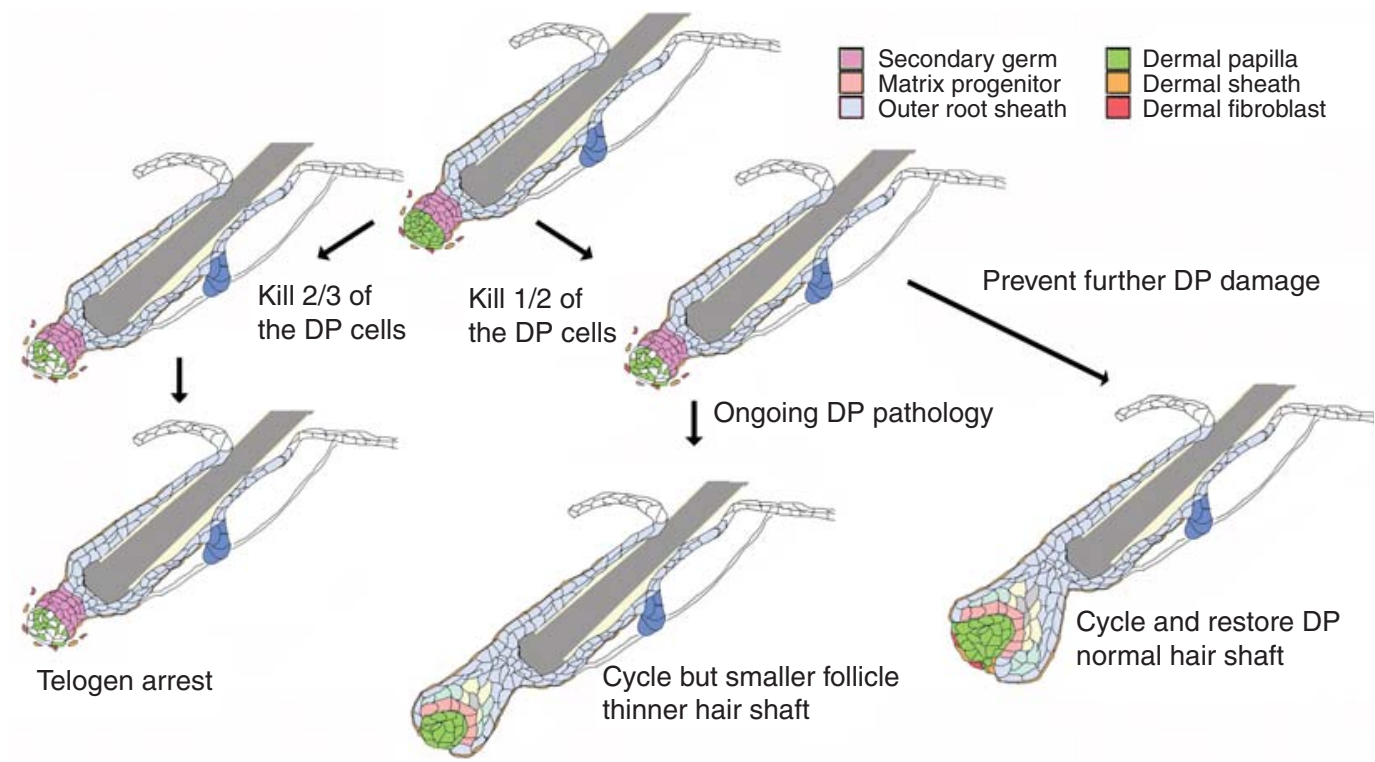

Figure 3. Changes in DP cell number can cause the follicular decline seen in progressive hair loss. Ablation of a fraction of DP cells in the telogen phase revealed that changes in DP cell number can cause the changes in hair structure and follicle cycling seen in progressive hair loss. Removal of approximately two-thirds of the DP cells caused arrest in the telogen phase. Removal of slightly fewer DP cells allowed reentry into the anagen phase. If the cause of DP cell damage was prevented, deleted DP cells were rapidly replaced and both hair shaft and follicle structure returned toward normal size. If further DP damage was not prevented, follicle size was reduced and a thinner hair shaft was formed (see Chi et al. 2013).

could be tracked, $\sim 1 \mathrm{wk}$. In a complementary approach, DP cells were ablated by the cell-typespecific expression of a toxin (Chi et al. 2013). In this case, some, but not all, DP cells were removed from most follicles (Fig. 3). When DP cell number was reduced, anagen initiation was delayed. Furthermore, follicles whose DP cell complement fell below a critical threshold number failed to reenter anagen and remained in the telogen phase when their neighbors entered the hair cycle. In contrast, follicles with a few more DP cells could go on to make a new hair. The phenotypes observed are consistent with the model that a critical level of signaling is required to initiate a self-reinforcing anagen phase. In DP depletion experiments, reduced numbers of DP cells reduce the aggregate signaling available for anagen initiation.

Although the act of reentering the anagen phase is specific to individual follicles, "macroenvironmental" factors coordinate the cycling behavior of follicles within a region. These in- clude signals from adjacent follicles as they enter anagen, input from other cell types in the skin, and hormonal signals generated outside the skin. The emerging model is that the same follicle-intrinsic signaling pathways that promote or inhibit anagen have been co-opted for interfollicular signaling to coordinate behavior between follicles (Botchkarev et al. 2001; Plikus et al. 2008, 2011; Plikus and Chuong 2008). Both adjacent follicles and other cell types in the skin may contribute signals that modulate the threshold for anagen entry (Plikus et al. 2008; Festa et al. 2011). The DP ablation experiments show that even in a macroenvironment that is permissive or stimulatory for anagen reentry, follicle-intrinsic signaling from the DP is critical for the decision to regenerate.

\section{DP FUNCTION DURING ANAGEN}

The correlation of DP size with both hair size and shape has suggested that DP might control 
The Dermal Papilla of the Hair Follicle

one or both of these characteristics. Unlike humans, in which the old hair is shed when the new hair is being generated, the club hair is retained in most mouse follicles over several cycles. This makes it possible to track the history of an individual follicle over time, with earlier hairs defining the activity of the follicle before an inducible perturbation. The partial DP ablation experiments described above confirmed that DP cell number is a determinant of hair size and morphology (Chi et al. 2013). Deletion of DP cells during the telogen phase had no shortterm effect on the epithelial follicle while it remained in telogen. However, follicles that had previously made an awl or auchene hair produced a zigzag hair when they reentered anagen with a reduced number of DP cells (Fig. 3).

There are several ways in which DP cell number can influence hair size and morphology. First, the DP is a physical niche for the progenitor cells that make the hair shaft. That niche role, if any, is apparently minor in the telogen phase. No striking alterations in the epithelial follicle are observed when the DP is deleted or diminished during the telogen phase (Rompolas et al. 2012; Chi et al. 2013). However, a reduced secondary germ is observed when DP cells are depleted in the preceding anagen/catagen phase, suggesting a niche function is required for formation of this structure during the catagen to telogen transition (Chi et al. 2013). In the anagen phase, contact with the DP defines the progenitor population and a change in DP size alters the number of progenitor cells that produce the hair (WY Chi and BA Morgan, unpubl.).

The DP also influences the size and shape of the hair shaft through the generation of signals that act on keratinocytes. A reduction in DP cell number alters signaling in two ways. First, for many signals, a net decrease in aggregate signaling/DP reflects a decreased DP cell number without a net change in gene expression per DP cell. However, the different hair types have both quantitative and qualitative differences in gene expression per DP cell (Driskell et al. 2009; Clavel et al. 2013). In the context of follicles that switch between the production of different hair types in successive hair cycles, this suggests that the aggregate signaling environment in larger hair bulbs allows the same DP cells to generate a qualitatively different instruction set.

\section{DP AND HAIR PIGMENTATION}

The DP also contributes to the regulation of hair pigmentation. Stem cell factor/kit ligand is expressed by the DP and required for the recruitment, differentiation, and maintenance of melanocytes that populate the hair bulb as it forms (Botchkareva et al. 2001). Endothelin 3 also promotes differentiation and proliferation of melanocytes (Baynash et al. 1994; Lahav et al. 1996) and is expressed by the DP (Rendl et al. 2005; Kaelin et al. 2013). In addition to recruiting and sustaining the melanocyte population, the DP also produces signals that modulate pigment production. In response to DP-derived Agouti signaling protein (Asip), melanocytes switch from production of dark black eumelanin to yellow pheomelanin (Bultman et al. 1992). Agouti expression early in the hair cycle generates a yellow band at the tip of the hair that creates the mottled brown appearance of many mice. Corin, a transmembrane protease expressed by the DP, modifies the length of the yellow band by partially opposing Asip activity (Enshell-Seijffers et al. 2008). Edn3 signaling can also promote the production of eumelanin over pheomelanin (Garcia et al. 2008). Changes in Corin and Agouti activity are linked to significant changes in pigmentation of wild mouse populations (Manceau et al. 2010, 2011; Linnen et al. 2013), while preferential Edn3 activity has been implicated in the darker pigmentation of spots and stripes in the cat family (Kaelin et al. 2013).

\section{TERMINATION OF ANAGEN}

In principle, cessation of DP growth promoting activity is sufficient to end the anagen phase. However, entry to the catagen phase is associated with augmented expression of genes that promote follicle regression as well. The best defined regulator of anagen length is FGF-5. Mutation of Fgf-5 leads to a prolonged anagen phase in many species (Hebert et al. 1994; Drogemuller et al. 2007; Cadieu et al. 2009). In the 
B.A. Morgan

mouse, $F g f-5$ is expressed in outer root sheath cells at the base of the follicle in late anagen, some of which abut the DP (Hebert et al. 1994). The mechanism and locus of Fgf-5 action remains unknown, but receptors that respond to Fgf-5 are expressed in the DP. Cultured DP cells stimulated with Fgf-2 produce factors that promote keratinocyte proliferation, and Fgf-5 can inhibit the production of these factors. While this shows that DP cells can respond to Fgf-5, further study is required to determine whether Fgf- 5 acts directly on DP to terminate anagen (Ota et al. 2002). In a similar fashion, other pathways that can promote catagen, including transforming growth factor- $\beta$ and neurotrophins, act in both epithelium and DP, and a specific role in DP has not been shown (Botchkarev and Paus 2003). Nevertheless, it is clear that activity of the DP can regulate the anagento-catagen transition. Follicles that lack $\beta$-catenin in the DP enter the catagen phase early (Enshell-Seijffers et al. 2010). Both reduced expression of growth promoting signals as well as premature expression of genes reported to promote catagen are observed in these DP.

\section{HOW IS DP SIZE MAINTAINED?}

The fact that the DP population in a follicle is not fixed, and yet DP populations and the hair coat change in predictable ways suggest that DP cell number is actively regulated. This was confirmed by DP cell ablation experiments (Fig. 3 ). When DP cell number was reduced during the telogen phase for the hair cycle, it remained reduced while the follicle persisted in the telogen phase. However, in follicles that reentered anagen, DP cell number was restored. This would suggest that a healthy and normal-sized epithelial compartment can either recruit new cells or sustain the proliferation of existing DP cells to regenerate its niche. During normal physiological enlargement of follicles, new cells are recruited to the DP (Fig. 4) (Chi et al. 2010). The source of additional DP cells during regeneration after damage has not been characterized. However, insights from the original formation of the DP may be instructive.
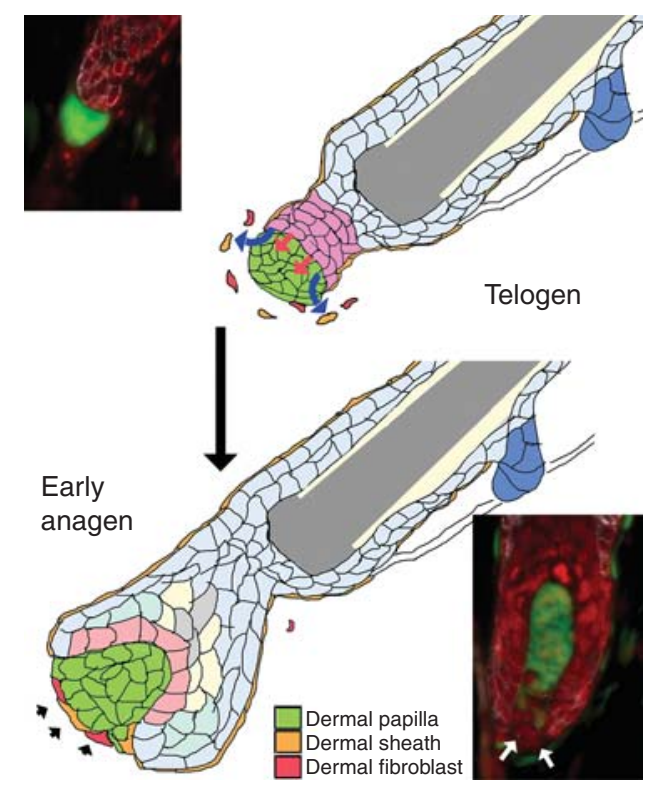

Figure 4. Increase in DP cell number during early anagen. During the telogen phase, the cells of the DP compact into a tight ball that abuts the secondary germ. Mesenchymal cells that may include remnants of the dermal sheath (orange) or dermal fibroblasts (red) are found close to the DP, but are not incorporated into it. At the start of anagen, new cells may be recruited to the base of the DP and adopt the expression of DP markers. Postulated signals from the secondary germ that mediate recruitment and expansion of the DP population are shown as red and blue arrows. Although both dermal sheath and fibroblasts are shown joining the DP (black arrowheads), the origin of these new DP cells has not been determined. The insets show lineage trace experiments in which the telogen DP is completely labeled with yellow fluorescent protein (YFP), whereas the subsequent early anagen DP shows new unlabeled cells at its base (based on Chi et al. 2010). Green, YFP; red, nuclei; white, k14.

\section{THE DP IS SPECIFIED BY PLACODAL SIGNALS}

During development, the epidermis plays an active role in specification of the follicular mesenchyme. The fact that dermis specifies pattern had led to the model that the initiation of appendage formation entailed a localized, patterned signal from the dermis that induced the overlying epidermal placode. This would imply that the precursor of the DP is a self-organizing 
entity that then recruits the follicular epithelium. Although this theory has not been disproved, the accumulated circumstantial evidence suggests the alternative model that the signal(s) that initiate placode development are more generally distributed in the superficial dermis. In this model, pattern arises in the epidermis in part because signaling within the plane of the epidermis restricts the response to inductive signals. This initiates the distinction between placodal and interplacodal fates. Only then does the nascent placode generate signals that recruit dermal cells to congregate beneath it to form the dermal condensate, the precursor to the DP.

Several observations support this model. First, no physical or molecular pattern has been detected in the dermis that precedes the specification of the epidermal placode. The advent of molecular markers of early placode formation has resolved older debate over whether early patterning events in the epidermis precede discernable physically patterned changes in the dermis (Noramly and Morgan 1998; SchmidtUllrich et al. 2006). The observation that a subset of the genes that become placodal markers initially show a diffuse expression pattern further supports the idea that a diffuse initial signal activates their expression (Noramly and Morgan 1998; Noramly et al. 1999; Lin et al. 2006; Zhang et al. 2009). The possibility of a local pattern of gene expression in the dermis that presages the pattern of epidermal placodes cannot be ruled out until all of the signals involved in follicle formation are defined. However, the discovery of feedback mechanisms acting within the epidermis that are capable of generating a patterned response to a more uniform inductive signal provide the mechanistic basis for an alternative explanation. Several signaling systems that are active in the epidermal placode initiate feedback loops that are formally similar to the reaction diffusion mechanisms capable of generating a patterned response from an initially uniform state within a two-dimensional space (Turing 1952; Noramly and Morgan 1998; Sick et al. 2006). Patterning is likely to incorporate the integration of multiple feedback systems that interact with each other in ways that extend well beyond the complexity of simple reaction diffusion, but the general principle that inhibitory feedback mechanisms can generate stable patterns is likely to apply.

This model does not exclude a role for localized signaling from the dermis in follicle formation. Instead, it places asymmetric signaling from the dermis downstream from initial patterning. Experiments showing that artificially generated asymmetries in dermal cell density can influence pattern are sometimes taken as evidence in support of a dermal prepattern model (Jiang et al. 1999), but these are also consistent with an epidermis-driven patterning model in which positive feedback reinforces an initial patterning decision. Such reinforcing feedback mechanisms are clearly evident. FGFs expressed by the epidermal placode play a central role in recruiting dermal cells to condense beneath it (Song et al. 1996, 2004; Wells et al. 2012; Huh et al. 2013). In mice or chickens harboring a mutation in FGF-20, the dermal condensate does not form, and although initial patterned expression of epidermal placode genes occurs, it does not fully resolve to a restricted pattern and subsequently fades as both epidermal and dermal cells adopt interfollicular fates (Houghton et al. 2007; Huh et al. 2013). These and other mutants that show transient epidermal patterning before a block of follicle maturation show that active communication between the epithelial and mesenchymal components of the nascent follicle are required to maintain initial fate decisions.

\section{WHAT CELLS CONTRIBUTE TO THE DP?}

If the epidermis recruits the DP, is there a distinct subpopulation in the dermis that is ether predetermined or specifically competent to become the DP? Multiple independent cells coalesce to form each DP (Collins et al. 2012). The dermal condensate fate is plastic and can be reversed after initial specification, either in mutants in which developmental progression is blocked or in tissue reconstruction experiments with dissociated dermal cells (Jiang et al. 1999; Houghton et al. 2007). If there is subset of dermal cells specifically competent to become DP, it is larger than those that normally adopt this 


\section{B.A. Morgan}

fate. As might be expected, lineage studies confirm that the superficial or "papillary" dermis forms the DP. However, this is not merely a reflection of the opportunity derived from their position adjacent to the nascent hair placode as these superficial cells also show preferential ability to form DP relative to cells derived from deeper in the dermis or hypodermis when tested in a skin reconstitution assay (Driskell et al. 2013). Nevertheless, the preponderance of the superficial dermis can be induced to express early condensate markers by forced activation of placodal signaling pathways in the embryo (Zhang et al. 2008, 2009). It is likely that superficial dermal cells retain this capacity in the adult. Forced activation of the $\beta$-catenin signal transduction pathways can induce de novo formation of hair follicles with DP in interfollicular epidermis (Lo Celso et al. 2004; Silva-Vargas et al. 2005). While the origin of these DP cells is not defined by these experiments, the fact that induced $\beta$-catenin activity in the epidermis causes a partial shift in adult dermal fibroblast gene expression toward that seen in the neonate suggests that superficial dermal cells respond to placode signals by becoming DP (Collins et al. 2011). These observations suggest that there is not a predetermined DP cell lineage and under appropriate conditions, superficial dermal cells can be recruited to adopt this fate by signals derived from keratinocytes.

\section{THE DP IN HAIR LOSS AND RESTORATION}

The reduction in the size of the hair follicle associated with progressive hair thinning and loss includes a failure to maintain DP cell number (Fig. 2) (Elliott et al. 1999). In androgenetic alopecia (male pattern baldness), several observations suggest that this arises from a primary defect in the DP. The pattern of hair loss reflects the differential embryological origins of frontoparietal and temporal/occipital scalp mesenchyme inferred from analysis in other mammals (Yoshida et al. 2008). Both classes of drugs that are effective in arresting the progression of hair loss, $5-\alpha$ reductase type 2 inhibitors and $K_{\mathrm{ATP}}$ channel openers, act on DP cells in culture or isolated hair follicles, although their activity in other tissues may contribute to their effectiveness in vivo (Kaufman et al. 1998; Randall 2008; Shorter et al. 2008). Other types of diffuse hair thinning and loss such as that observed with aging may reflect a primary defect in either compartment of the hair follicle that manifests in part as a failure to maintain DP cell number. Our evolving understandings of the mechanisms that normally specify and maintain DP cell number suggest novel approaches to preventing hair loss or repairing declining follicles.

Currently, hair loss is often repaired by transplanting hair follicles from unaffected regions of the scalp. The success of this technique may rely on the distinct origins of the mesenchyme from which the DP is derived in different regions of the scalp. Both the cost and labor involved in preparing and implanting follicular units and the limitations on the numbers of follicles available for transplantation have prompted a search for alternative approaches. The experimental analysis of DP cell function has shown that, under appropriate conditions, implanted DP can induce new hair follicles in rodents. One focus of effort has been on replacing injured hair follicles from scratch, essentially recapitulating the developmental process in vivo or in vitro. Methods for the expansion of both rodent and human DP cells in culture that either maintain or restore their trichogenic activity have been reported (Kishimoto et al. 2000; Shimizu and Morgan 2004; Osada et al. 2007; Rendl et al. 2008; Soma et al. 2012; Huang et al. 2013; Thangapazham et al. 2014). The trichogenic activity of human DP cells has been shown on murine keratinocytes. Similar efforts with human keratinocytes have led to formation of arrested, aberrant follicles, but recent modifications to this approach have shown promise, including, in rare cases, the generation of small hairs in human skin xenografts (Higgins et al. 2014). In principle, further progress may lead to the use of such culture-expanded DP cells for autologous implants that might induce new hair follicles. However, as we come to understand the intrinsic mechanisms in healthy hair follicles that attract cells to the DP and maintain them once they are there (Fig. 4), an alternative approach to cell-based therapy may 
hold promise. Experiments in rodents showed that cells derived from the DP or proximal dermal sheath can incorporate into exiting hair follicles (McElwee et al. 2003; Biernaskie et al. 2009). This is apparently most efficient during the early anagen phase, when new cells are normally recruited to the DP (Biernaskie et al. 2009; Chi et al. 2010). Anectdotal reports of hair follicle induction in humans after dermal sheath cell implantation do not distinguish between these alternative mechanisms of incorporation and follicle neogenesis (Reynolds et al. 1999), but suggest that the techniques developed in rodents hold promise for adaptation to clinical application with further research. This may include enhancing the signals that recruit or maintain the endogenous cells in thinning scalp, or enhancing the efficiency with which injected cells are incorporated into existing follicles.

\section{CONCLUSION}

A rich history of experimental analysis has shown that the DP plays a key role in specifying the size, shape, and color of the hair as well as the frequency with which it regenerates. The molecular signals that mediate the interaction of the DP with matrix keratinocytes to generate the hair shaft are being rapidly characterized. Interaction with keratinocytes is also critical for the maintenance of the DP. Recent work focuses attention on the transitions to and from the resting telogen phase as critical periods for successful maintenance of DP and, ultimately, hair size. Current work to understand which cells in adult skin can be recruited to become DP, and what signals mediate this recruitment and regulate proliferation or survival of DP cells hold promise for novel approaches to managing hair loss.

\section{REFERENCES}

Baynash AG, Hosoda K, Giaid A, Richardson JA, Emoto N, Hammer RE, Yanagisawa M. 1994. Interaction of endothelin-3 with endothelin-B receptor is essential for development of epidermal melanocytes and enteric neurons. Cell 79: 1277-1285.

Biernaskie J, Paris M, Morozova O, Fagan BM, Marra M, Pevny L, Miller FD. 2009. SKPs derive from hair follicle precursors and exhibit properties of adult dermal stem cells. Cell Stem Cell 5: 610-623.

Botchkarev VA, Paus R. 2003. Molecular biology of hair morphogenesis: Development and cycling. J Exp Zool B Mol Dev Evol 298: 164-180.

Botchkarev VA, Botchkareva NV, Nakamura M, Huber O, Funa K, Lauster R, Paus R, Gilchrest BA. 2001. Noggin is required for induction of the hair follicle growth phase in postnatal skin. FASEB J 15: 2205-2214.

Botchkareva NV, Khlgatian M, Longley BJ, Botchkarev VA, Gilchrest BA. 2001. SCF/c-kit signaling is required for cyclic regeneration of the hair pigmentation unit. FASEB J 15: 645-658.

Bultman SJ, Michaud EJ, Woychik RP. 1992. Molecular characterization of the mouse agouti locus. Cell 71: 11951204.

Cadieu E, Neff MW, Quignon P, Walsh K, Chase K, Parker HG, Vonholdt BM, Rhue A, Boyko A, Byers A, et al. 2009. Coat variation in the domestic dog is governed by variants in three genes. Science 326: 150-153.

Chi WY, Enshell-Seijffers D, Morgan BA. 2010. De novo production of dermal papilla cells during the anagen phase of the hair cycle. J Invest Dermatol 130: 2664-2666.

Chi W, Wu E, Morgan BA. 2013. Dermal papilla cell number specifies hair size, shape and cycling and its reduction causes follicular decline. Development 140: 1676-1683.

Clavel C, Grisanti L, Zemla R, Rezza A, Barros R, Sennett R, Mazloom AR, Chung CY, Cai X, Cai CL, et al. 2013. Sox2 in the dermal papilla niche controls hair growth by finetuning BMP signaling in differentiating hair shaft progenitors. Dev Cell 23: 981-994.

Collins CA, Kretzschmar K, Watt FM. 2011. Reprogramming adult dermis to a neonatal state through epidermal activation of $\beta$-catenin. Development 138: 5189-5199.

Collins CA, Jensen KB, MacRae EJ, Mansfield W, Watt FM. 2012. Polyclonal origin and hair induction ability of dermal papillae in neonatal and adult mouse back skin. Dev Biol 366: 290-297.

Dhouailly D. 1973. Dermo-epidermal interactions between birds and mammals: Differentiation of cutaneous appendages. J Embryol Exp Morphol 30: 587-603.

Dhouailly D, Prin F, Kanzler B, Viallet J. 1998. Variation of cutaneous appendages: Regional specification and crossspecies signals. In Molecular basis of epithelial appendage morphogenesis (ed. Chuong C), pp. 45-56. RG Landes, Austin, TX.

Drew CF, Lin CM, Jiang TX, Blunt G, Mou C, Chuong CM, Headon DJ. 2007. The Edar subfamily in feather placode formation. Dev Biol 305: 232-245.

Driskell RR, Giangreco A, Jensen KB, Mulder KW, Watt FM. 2009. Sox2-positive dermal papilla cells specify hair follicle type in mammalian epidermis. Development 136: 2815-2823.

Driskell RR, Lichtenberger BM, Hoste E, Kretzschmar K, Simons BD, Charalambous M, Ferron SR, Herault Y, Pavlovic G, Ferguson-Smith AC, et al. 2013. Distinct fibroblast lineages determine dermal architecture in skin development and repair. Nature 504: 277-281.

Drogemuller C, Rufenacht S, Wichert B, Leeb T. 2007. Mutations within the FGF-5 gene are associated with hair length in cats. Anim Genet 38: 218-221. 
B.A. Morgan

Dry F. 1927. The coat of the mouse. J Genet 16: 281-340.

Elliott K, Stephenson TJ, Messenger AG. 1999. Differences in hair follicle dermal papilla volume are due to extracellular matrix volume and cell number: Implications for the control of hair follicle size and androgen responses. J Invest Dermatol 113: 873-877.

Enshell-Seijffers D, Lindon C, Morgan BA. 2008. The serine protease Corin is a novel modifier of the Agouti pathway. Development 135: 217-225.

Enshell-Seijffers D, Lindon C, Kashiwagi M, Morgan BA. 2010. $\beta$-catenin activity in the dermal papilla regulates morphogenesis and regeneration of hair. Dev Cell 18: 633-642.

Festa E, Fretz J, Berry R, Schmidt B, Rodeheffer M, Horowitz M, Horsley V. 2011. Adipocyte lineage cells contribute to the skin stem cell niche to drive hair cycling. Cell 146: 761-771.

Garcia RJ, Ittah A, Mirabal S, Figueroa J, Lopez L, Glick AB, Kos L. 2008. Endothelin 3 induces skin pigmentation in a keratin-driven inducible mouse model. J Invest Dermatol 128: $131-142$.

Greco V, Chen T, Rendl M, Schober M, Pasolli HA, Stokes N, Dela Cruz-Racelis J, Fuchs E. 2009. A two-step mechanism for stem cell activation during hair regeneration. Cell Stem Cell 4: 155-169.

Hebert JM, Rosenquist T, Gotz J, Martin GR. 1994. FGF-5 as a regulator of the hair growth cycle: Evidence from targeted and spontaneous mutations. Cell 78: 1017-1025.

Higgins CA, Chen JC, Cerise JE, Jahoda CA, Christiano AM. 2014. Microenvironmental reprogramming by three-dimensional culture enables dermal papilla cells to induce de novo human hair-follicle growth. Proc Natl Acad Sci 110: 19679-19688.

Houghton L, Lindon C, Morgan BA. 2005. The ectodysplasin pathway in feather tract development. Development 132: $863-872$.

Houghton L, Lindon CM, Freeman A, Morgan BA. 2007. Abortive placode formation in the feather tract of the scaleless chicken embryo. Dev Dyn 236: 3020-3030.

Huang YC, Chan CC, Lin WT, Chiu HY, Tsai RY, Tsai TH, Chan JY, Lin SJ. 2013. Scalable production of controllable dermal papilla spheroids on PVA surfaces and the effects of spheroid size on hair follicle regeneration. Biomaterials 34: $442-451$.

Huh SH, Narhi K, Lindfors PH, Haara O, Yang L, Ornitz DM, Mikkola ML. 2013. Fgf-20 governs formation of primary and secondary dermal condensations in developing hair follicles. Genes Dev 27: 450-458.

Ibrahim L, Wright EA. 1982. A quantitative study of hair growth using mouse and rat vibrissal follicles: I. Dermal papilla volume determines hair volume. J Embryol Exp Morphol 72: 209-224.

Ito M, Kizawa K, Hamada K, Cotsarelis G. 2004. Hair follicle stem cells in the lower bulge form the secondary germ, a biochemically distinct but functionally equivalent progenitor cell population, at the termination of catagen. Differentiation 72: 548-557.

Ito M, Yang Z, Andl T, Cui C, Kim N, Millar SE, Cotsarelis G. 2007. Wnt-dependent de novo hair follicle regeneration in adult mouse skin after wounding. Nature 447: 316-320.
Jiang TX, Jung HS, Widelitz RB, Chuong CM. 1999. Selforganization of periodic patterns by dissociated feather mesenchymal cells and the regulation of size, number and spacing of primordia. Development 126: 4997-5009.

Jung HS, Francis-West PH, Widelitz RB, Jiang TX, TingBerreth S, Tickle C, Wolpert L, Chuong CM. 1998. Local inhibitory action of BMPs and their relationships with activators in feather formation: Implications for periodic patterning. Dev Biol 196: 11-23.

Kaelin CB, Xu X, Hong LZ, David VA, McGowan KA, Schmidt-Kuntzel A, Roelke ME, Pino J, Pontius J, Cooper GM, et al. 2013. Specifying and sustaining pigmentation patterns in domestic and wild cats. Science 337: 15361541.

Kaufman KD, Olsen EA, Whiting D, Savin R, DeVillez R, Bergfeld W, Price VH, Van Neste D, Roberts JL, Hordinsky M, et al. 1998. Finasteride in the treatment of men with androgenetic alopecia. Finasteride Male Pattern Hair Loss Study Group. J Am Acad Dermatol 39: 578589.

Kimura-Ueki M, Oda Y, Oki J, Komi-Kuramochi A, Honda E, Asada M, Suzuki M, Imamura T. 2012. Hair cycle resting phase is regulated by cyclic epithelial FGF-18 signaling. J Invest Dermatol 132: 1338-1345.

Kishimoto J, Burgeson RE, Morgan BA. 2000. Wnt signaling maintains the hair-inducing activity of the dermal papilla. Genes Dev 14: 1181-1185.

Kobielak K, Stokes N, de la Cruz J, Polak L, Fuchs E. 2007. Loss of a quiescent niche but not follicle stem cells in the absence of bone morphogenetic protein signaling. Proc Natl Acad Sci 104: 10063-10068.

Kollar EJ. 1970. The induction of hair follicles by embryonic dermal papillae. J Invest Dermatol 55: 374-378.

Lahav R, Ziller C, Dupin E, Le Douarin NM. 1996. Endothelin 3 promotes neural crest cell proliferation and mediates a vast increase in melanocyte number in culture. Proc Natl Acad Sci 93: 3892-3897.

Laurikkala J, Pispa J, Jung HS, Nieminen P, Mikkola M, Wang X, Saarialho-Kere U, Galceran J, Grosschedl R, Thesleff I. 2002. Regulation of hair follicle development by the TNF signal ectodysplasin and its receptor Edar. Development 129: 2541-2553.

Legue E, Nicolas JF. 2005. Hair follicle renewal: Organization of stem cells in the matrix and the role of stereotyped lineages and behaviors. Development 132: 4143-4154.

Leishman E, Howard JM, Garcia GE, Miao Q, Ku AT, Dekker JD, Tucker H, Nguyen H. 2013. Foxp1 maintains hair follicle stem cell quiescence through regulation of Fgf18. Development 140: 3809-3818.

Li L, Rutlin M, Abraira VE, Cassidy C, Kus L, Gong S, Jankowski MP, Luo W, Heintz N, Koerber HR, et al. 2012. The functional organization of cutaneous lowthreshold mechanosensory neurons. Cell 147: $1615-$ 1627.

Lillie F, Wang H. 1941. Physiology and development of the feather: V. Experimental morphogenesis. Physiol Zool 14: $103-133$.

Lin CM, Jiang TX, Widelitz RB, Chuong CM. 2006. Molecular signaling in feather morphogenesis. Curr Opin Cell Biol 18: 730-741. 
Linnen CR, Poh YP, Peterson BK, Barrett RD, Larson JG, Jensen JD, Hoekstra HE. 2013. Adaptive evolution of multiple traits through multiple mutations at a single gene. Science 339: 1312-1316.

Lo Celso C, Prowse DM, Watt FM. 2004. Transient activation of $\beta$-catenin signalling in adult mouse epidermis is sufficient to induce new hair follicles but continuous activation is required to maintain hair follicle tumours. Development 131: 1787-1799.

Manceau M, Domingues VS, Linnen CR, Rosenblum EB, Hoekstra HE. 2010. Convergence in pigmentation at multiple levels: Mutations, genes and function. Philos Trans R Soc Lond B Biol Sci 365: 2439-2450.

Manceau M, Domingues VS, Mallarino R, Hoekstra HE. 2011. The developmental role of Agouti in color pattern evolution. Science 331: 1062-1065.

McElwee KJ, Kissling S, Wenzel E, Huth A, Hoffmann R. 2003. Cultured peribulbar dermal sheath cells can induce hair follicle development and contribute to the dermal sheath and dermal papilla. J Invest Dermatol 121: 1267 1275.

Miranda BH, Tobin DJ, Sharpe DT, Randall VA. 2010. Intermediate hair follicles: A new more clinically relevant model for hair growth investigations. Br J Dermatol 163: $287-295$.

Morgan BA, Orkin RW, Noramly S, Perez A. 1998. Stagespecific effects of sonic hedgehog expression in the epidermis. Dev Biol 201: 1-12.

Muller-Rover S, Handjiski B, van der Veen C, Eichmuller S, Foitzik K, McKay IA, Stenn KS, Paus R. 2001. A comprehensive guide for the accurate classification of murine hair follicles in distinct hair cycle stages. J Invest Dermatol 117: 3-15.

Noramly S, Morgan BA. 1998. BMPs mediate lateral inhibition at successive stages in feather tract development. Development 125: 3775-3787.

Noramly S, Freeman A, Morgan BA. 1999. $\beta$-catenin signaling can initiate feather bud development. Development 126: $3509-3521$.

Oliver RF. 1967. Ectopic regeneration of whiskers in the hooded rat from implanted lengths of vibrissa follicle wall. J Embryol Exp Morphol 17: 27-34.

Oliver RF. 1970. The induction of hair follicle formation in the adult hooded rat by vibrissa dermal papillae. J Embryol Exp Morphol 23: 219-236.

Osada A, Iwabuchi T, Kishimoto J, Hamazaki TS, Okochi H. 2007. Long-term culture of mouse vibrissal dermal papilla cells and de novo hair follicle induction. Tissue Eng 13: $975-982$.

Ota Y, Saitoh Y, Suzuki S, Ozawa K, Kawano M, Imamura T. 2002. Fibroblast growth factor 5 inhibits hair growth by blocking dermal papilla cell activation. Biochem Biophys Res Commun 290: 169-176.

Pisansarakit P, Moore GP. 1986. Induction of hair follicles in mouse skin by rat vibrissa dermal papillae. J Embryol Exp Morphol 94: 113-119.

Plikus MV, Chuong CM. 2008. Complex hair cycle domain patterns and regenerative hair waves in living rodents. $J$ Invest Dermatol 128: 1071-1080.

Plikus MV, Mayer JA, de la Cruz D, Baker RE, Maini PK, Maxson R, Chuong CM. 2008. Cyclic dermal BMP sig- nalling regulates stem cell activation during hair regeneration. Nature 451: 340-344.

Plikus MV, Baker RE, Chen CC, Fare C, de la Cruz D, Andl T, Maini PK, Millar SE, Widelitz R, Chuong CM. 2011. Selforganizing and stochastic behaviors during the regeneration of hair stem cells. Science 332: 586-589.

Randall VA. 2008. Androgens and hair growth. Dermatol Ther 21: 314-328.

Reddy S, Andl T, Bagasra A, Lu MM, Epstein DJ, Morrisey EE, Millar SE. 2001. Characterization of Wnt gene expression in developing and postnatal hair follicles and identification of Wnt5a as a target of Sonic hedgehog in hair follicle morphogenesis. Mech Dev 107: 69-82.

Rendl M, Lewis L, Fuchs E. 2005. Molecular dissection of mesenchymal-epithelial interactions in the hair follicle. PLoS Biol 3: e331.

Rendl M, Polak L, Fuchs E. 2008. BMP signaling in dermal papilla cells is required for their hair follicle-inductive properties. Genes Dev 22: 543-557.

Reynolds AJ, Jahoda CA. 1992. Cultured dermal papilla cells induce follicle formation and hair growth by transdifferentiation of an adult epidermis. Development 115: $587-$ 593.

Reynolds AJ, Lawrence C, Cserhalmi-Friedman PB, Christiano AM, Jahoda CA. 1999. Trans-gender induction of hair follicles. Nature 402: 33-34.

Rompolas P, Deschene ER, Zito G, Gonzalez DG, Saotome I, Haberman AM, Greco V. 2012. Live imaging of stem cell and progeny behaviour in physiological hair-follicle regeneration. Nature 487: 496-499.

Schmidt-Ullrich R, Tobin DJ, Lenhard D, Schneider P, Paus R, Scheidereit C. 2006. NF- $\kappa$ B transmits Eda Al/EdaR signalling to activate Shh and cyclin D1 expression, and controls post-initiation hair placode down growth. Development 133: 1045-1057.

Scott EV, Eckel T. 1958. Geometric relationships between the matrix of the hair bulb and its dermal papilla in normal and alopecic scalp. J Invest Dermatol 31: 281-289.

Sharov AA, Sharova TY, Mardaryev AN, Tommasi di Vignano A, Atoyan R, Weiner L, Yang S, Brissette JL, Dotto GP, Botchkarev VA. 2006. Bone morphogenetic protein signaling regulates the size of hair follicles and modulates the expression of cell cycle-associated genes. Proc Natl Acad Sci 103: 18166-18171.

Shimizu H, Morgan BA. 2004. Wnt signaling through the $\beta$ catenin pathway is sufficient to maintain, but not restore, anagen-phase characteristics of dermal papilla cells. J Invest Dermatol 122: 239-245.

Shorter K, Farjo NP, Picksley SM, Randall VA. 2008. Human hair follicles contain two forms of ATP-sensitive potassium channels, only one of which is sensitive to minoxidil. FASEB J 22: 1725-1736.

Sick S, Reinker S, Timmer J, Schlake T. 2006. WNT and DKK determine hair follicle spacing through a reaction-diffusion mechanism. Science 314: 1447-1450.

Silva-Vargas V, Lo Celso C, Giangreco A, Ofstad T, Prowse DM, Braun KM, Watt FM. 2005. $\beta$-catenin and Hedgehog signal strength can specify number and location of hair follicles in adult epidermis without recruitment of bulge stem cells. Dev Cell 9: 121-131. 
B.A. Morgan

Soma T, Fujiwara S, Shirakata Y, Hashimoto K, Kishimoto J. 2012. Hair-inducing ability of human dermal papilla cells cultured under Wnt $/ \beta$-catenin signalling activation. Exp Dermatol 21: 307-309.

Song H, Wang Y, Goetinck PF. 1996. Fibroblast growth factor 2 can replace ectodermal signaling for feather development. Proc Natl Acad Sci 93: 10246-10249.

Song HK, Lee SH, Goetinck PF. 2004. FGF-2 signaling is sufficient to induce dermal condensations during feather development. Dev Dyn 231: 741-749.

Stenn KS, Paus R. 2001. Controls of hair follicle cycling. Physiol Rev 81: 449-494.

Sun TT, Cotsarelis G, Lavker RM. 1991. Hair follicular stem cells: The bulge-activation hypothesis. J Invest Dermatol 96: $77 \mathrm{~S}-78 \mathrm{~S}$.

Thangapazham RL, Klover P, Wang JA, Zheng Y, Devine A Li S, Sperling L, Cotsarelis G, Darling TN. 2014. Dissociated human dermal papilla cells induce hair follicle neogenesis in grafted dermal-epidermal composites. $J$ Invest Dermatol 134: 538-540.

Turing AM. 1952. The chemical basis of morphogenesis. Phil Trans R Soc Lond B 237: 37-72.

Van Mater D, Kolligs FT, Dlugosz AA, Fearon ER. 2003. Transient activation of $\beta$-catenin signaling in cutaneous keratinocytes is sufficient to trigger the active growth phase of the hair cycle in mice. Genes Dev 17: 12191224.

Wang H. 1943. Morphogentic functions of the epidermal and dermal components of the papilla in feather regeneration. Physiol Zool 16: 325-350.

Wells KL, Hadad Y, Ben-Avraham D, Hillel J, Cahaner A, Headon DJ. 2012. Genome-wide SNP scan of pooled DNA reveals nonsense mutation in FGF-20 in the scaleless line of featherless chickens. BMC Genomics 13: 257.

Yoshida T, Vivatbutsiri P, Morriss-Kay G, Saga Y, Iseki S. 2008. Cell lineage in mammalian craniofacial mesenchyme. Mech Dev 125: 797-808.

Zhang Y, Andl T, Yang SH, Teta M, Liu F, Seykora JT, Tobias JW, Piccolo S, Schmidt-Ullrich R, Nagy A, et al. 2008. Activation of $\beta$-catenin signaling programs embryonic epidermis to hair follicle fate. Development 135: 2161 2172.

Zhang Y, Tomann P, Andl T, Gallant NM, Huelsken J, Jerchow B, Birchmeier W, Paus R, Piccolo S, Mikkola ML, et al. 2009. Reciprocal requirements for EDA/EDAR/ $\mathrm{NF}-\kappa \mathrm{B}$ and Wnt/ $\beta$-catenin signaling pathways in hair follicle induction. Dev Cell 17: 49-61. 


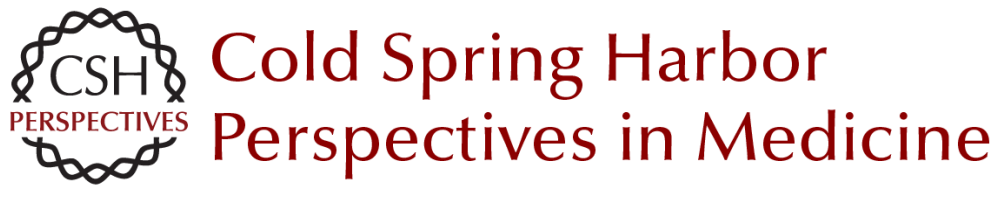

\section{The Dermal Papilla: An Instructive Niche for Epithelial Stem and Progenitor Cells in Development and Regeneration of the Hair Follicle}

Bruce A. Morgan

Cold Spring Harb Perspect Med 2014; doi: 10.1101/cshperspect.a015180

Subject Collection The Skin and Its Diseases

Melanoma: Clinical Features and Genomic

Insights

Elena B. Hawryluk and Hensin Tsao

Wound Healing and Skin Regeneration Makoto Takeo, Wendy Lee and Mayumi Ito

The Dermal Papilla: An Instructive Niche for Epithelial Stem and Progenitor Cells in

Development and Regeneration of the Hair Follicle Bruce A. Morgan

Immunology and Skin in Health and Disease Jillian M. Richmond and John E. Harris

Desmosomes: Regulators of Cellular Signaling and Adhesion in Epidermal Health and Disease Jodi L. Johnson, Nicole A. Najor and Kathleen J. Green

Markers of Epidermal Stem Cell Subpopulations

in Adult Mammalian Skin Kai Kretzschmar and Fiona M. Watt

Psoriasis

Paola Di Meglio, Federica Villanova and Frank O. Nestle

Cell Therapy in Dermatology

Gabriela Petrof, Alya Abdul-Wahab and John A. McGrath
Modeling Cutaneous Squamous Carcinoma

Development in the Mouse

Phillips Y. Huang and Allan Balmain

Natural and Sun-Induced Aging of Human Skin Laure Rittié and Gary J. Fisher

Advanced Treatment for Basal Cell Carcinomas Scott X. Atwood, Ramon J. Whitson and Anthony E. Oro

Epidermal Polarity Genes in Health and Disease Frederik Tellkamp, Susanne Vorhagen and Carien M. Niessen

Induced Pluripotent Stem Cells in Dermatology:

Potentials, Advances, and Limitations Ganna Bilousova and Dennis R. Roop

The Genetics of Human Skin Disease Gina M. DeStefano and Angela M. Christiano

p53/p63/p73 in the Epidermis in Health and Disease

Vladimir A. Botchkarev and Elsa R. Flores

Diversification and Specialization of Touch

Receptors in Skin

David M. Owens and Ellen A. Lumpkin

For additional articles in this collection, see http://perspectivesinmedicine.cshlp.org/cgi/collection/ 